\title{
Hospitalization rate and 30-day mortality among patients with status asthmaticus in Denmark: a I6-year nationwide population-based cohort study
}

\author{
This article was published in the following Dove Press journal: \\ Clinical Epidemiology \\ 4 September 2013 \\ Number of times this article has been viewed
}

Jennie Maria Christin Strid'

Henrik Gammelager'

Martin Berg Johansen'

Else Tønnesen ${ }^{2}$

Christian Fynbo

Christiansen'

'Department of Clinical Epidemiology, Aarhus University Hospital, Aarhus N, Denmark; ${ }^{2}$ Department of

Anesthesiology and Intensive Care Medicine, Aarhus University Hospital,

Aarhus C, Denmark
Correspondence: Jennie Maria Christin Strid

Department of Clinical Epidemiology, Aarhus University Hospital, Olof Palmes Allé 43-45, DK-82 I0 Aarhus N, Denmark Tel +4587 I 68063, +4523420949

Fax +45 87I 672I5

Email jmc@strid.se
Objective: Current data on hospitalization and prognosis of acute asthma and status asthmaticus are inconclusive. We aim to analyze the rate of first-time hospitalizations for status asthmaticus among patients of all ages, the proportion admitted to intensive care units (ICU), and the 30-day mortality over a 16-year period.

Methods: In this population-based cohort study, we used medical registries to identify all first-time status asthmaticus hospitalizations in Denmark from 1996 through 2011. Data on comorbidities were also obtained. We computed yearly hospitalization rates overall and by gender and age groups, and estimated the proportion requiring ICU admission. We estimated 30-day age- and gender-standardized mortality. We examined potential misclassification from acute exacerbation of chronic obstructive pulmonary disease (COPD) by excluding patients with preexisting or concurrent COPD.

Results: Of the 5,001 patients identified with a first-time status asthmaticus hospitalization, $50.5 \%$ were male, $40.3 \%$ were $<15$ years old, and $12.4 \%$ had comorbidity. The hospitalization rate increased from 48.0 per 1,000,000 person-years (PY) $(95 \%$ confidence interval [CI]: 45.1-51.1 PY) during 1996-1999 to 70.1 per 1,000,000 PY (95\% CI: 66.7-73.7 PY) during 2008-2011. This may be explained by an increased hospitalization rate of children. The standardized 30-day mortality risk declined from 3.3\% (95\% CI: $2.5 \%-4.1 \%$ ) in $1996-1999$ to $1.5 \%$ (95\% CI: 0.9\%-2.1\%) in 2008-2011. During 2005-2011, 10.1\% of status asthmaticus patients were admitted to the ICU. Hospitalization rates and mortality risk decreased by excluding 939 patients also registered with COPD, but overall temporal changes did not change.

Conclusion: From 1996 to 2011, status asthmaticus hospitalization rate increased but remained below 100 hospitalizations per 1,000,000 PY. Thirty-day mortality risk was halved to less than $2 \%$.

Keywords: incidence, prognosis, cohort study, hospitalization, mortality, status asthmaticus

\section{Introduction}

Status asthmaticus is a life-threatening medical emergency, defined as an acute exacerbation of asthma that is refractory to initial standard treatment. ${ }^{1-4}$ Status asthmaticus involves a risk of respiratory failure, and intensive care may be needed. ${ }^{5}$ The prevalence of asthma has increased for decades, although some data now indicate a stable prevalence within the last decade. ${ }^{6-11}$ The World Health Organization reported in 2007 that 300 million people worldwide had asthma, and reported asthma as the most common chronic disease among children. ${ }^{12,13}$ 
Current data about hospitalization rates and prognosis of

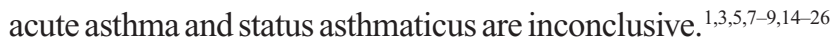
We identified 19 studies on status asthmaticus hospitalizations and prognosis using the definition of status asthmaticus provided above. ${ }^{1,3,5,7-9,14-26}$ These studies were restricted

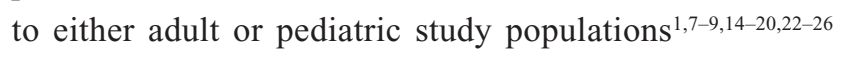
or were limited to a few hospitals or intensive care units (ICUs), ${ }^{7,8,14,15,18,21,23,25,26}$ reducing generalizability. Furthermore, 14 studies included readmissions, ${ }^{1,7,8,14-16,18-21,23-26}$ which may affect estimates of hospitalization rates and prognosis due to the increased risk of further admissions and worsened prognosis. ${ }^{7}$ A large population-based longitudinal study of patients of all ages is needed to provide more accurate estimates of hospitalization rate and prognosis of first-time status asthmaticus episodes.

We conducted a registry-based longitudinal cohort study, encompassing all first-time pediatric and adult hospitalizations for status asthmaticus registered in Denmark during the past 16 years, to analyze changes in hospitalization rates and 30-day mortality, and to assess the proportion of status asthmaticus patients admitted to an ICU.

\section{Methods and materials}

\section{Study design and setting}

We conducted this cohort study using population-based medical registries in Denmark.

The Danish population (approximately 5.5 million persons ${ }^{27}$ ) has unfettered access to outpatient and inpatient medical care through the tax-funded national health care system. We linked population databases at the individual level using the unique Danish 10-digit identification number (CPR) assigned to all Danish residents by the Danish Civil Registration System since January 1, 1968. ${ }^{28}$

\section{Patients with status asthmaticus}

We identified all Danish residents hospitalized with a firsttime primary or secondary diagnosis of status asthmaticus from January 1, 1996 to December 31, 2011, by searching the Danish National Patient Registry (NPR). ${ }^{29}$ The study period was based on the availability of relevant registries and allows an implementation period of the International Classification of Diseases, 10th revision (ICD-10) introduced in Denmark in 1994. We eliminated recurrent status asthmaticus by omitting subjects with a diagnosis of status asthmaticus from 1980 through 1995.

The NPR, established in 1977, contains virtually complete information on patient contacts with Danish nonpsychiatric hospitals. Since 1995, the NPR also has included data on outpatient clinic and emergency department visits. ${ }^{29,30}$ Data on ICU admissions have been routinely recorded since $2005,{ }^{31}$ enabling us to assess the proportion of patients admitted to an ICU during the last 7 years of the study period.

Records in the NPR contain hospital and department codes, admission and discharge dates, diagnoses (one primary diagnosis and up to 19 secondary diagnoses) assigned by the discharging physicians, major medical treatments, and surgical procedures. Diagnoses have been coded according to the Danish version of the International Classification of Diseases, 8th revision (ICD-8) from 1977 to 1993 and according to the ICD-10 since 1994. The International Classification of Diseases, 9th revision (ICD-9) has never been used in Denmark. We used the ICD-8 code and the ICD-10 code for status asthmaticus (Appendix 1) to identify all patients with a primary or secondary inpatient diagnosis of status asthmaticus.

\section{Demographics and mortality}

We obtained data from the Danish Civil Registration System on gender, age, and date of death in deceased patients. The Civil Registration System is electronically updated daily and contains complete information for all Danish residents on gender, residence, vital status, and dates of birth, death, and emigration.

\section{Comorbidity}

We obtained information from the NPR on diagnoses of comorbid conditions included in the Charlson Comorbidity Index (CCI). ${ }^{32}$ We included all inpatient and outpatient clinic diagnoses recorded within 5 years before the current status asthmaticus hospitalization. The CCI, a widely used comorbidity scoring system adapted for hospital discharge data, includes 19 conditions (Appendix 1). ${ }^{33}$ Each condition is assigned a weight between one and six, reflecting prognostic impact, and the CCI score is computed as the sum of the weights. We defined three levels of comorbidity severity based on the CCI scores: 0 (low comorbidity level), 1-2 (medium comorbidity level), and $\geq 3$ (high comorbidity level). We excluded chronic pulmonary diseases from the $\mathrm{CCI}$, but included chronic obstructive pulmonary disease (COPD) (Appendix 1) as a separate comorbidity, because an acute exacerbation of COPD can be clinically difficult to distinguish from status asthmaticus and can therefore cause possible misclassification. ${ }^{34}$

\section{Validation of the status asthmaticus diagnosis in the NPR}

To validate the diagnosis of status asthmaticus in the NPR, we randomly selected three patients per calendar year, from 
January 1, 1994 to December 31, 2009, from a subset of our North Jutland cohort and retrieved their hospital discharge summaries. Based on the current definition of status asthmaticus $^{1-4}$ and the level of details available in the discharge summaries, the diagnosis was confirmed when $\geq 2$ of the following criteria were fulfilled: (1) presence of asthma symptoms (ie, dyspnea, wheezing, cough, chest tightness, and/or decreased peak flow); (2) the condition was refractory to standard initial treatment (inhalation of bronchodilators and/or steroids) and hospitalization was required; and (3) the condition was a medical emergency. A researcher with a Bachelor of Medical Science degree (JMCS) reviewed all the discharge records, and a physician $(\mathrm{HG})$ re-reviewed the discharge records in cases of uncertainty. If disagreement occurred, a second physician (CFC) assessed the discharge record in question, and the majority determined the outcome. We calculated the positive predictive value of the NPR status asthmaticus diagnosis as the percentage of our random sample with an NPR status asthmaticus diagnosis that was confirmed by review of the discharge record, ${ }^{35}$ according to the algorithm presented above. The exact $95 \%$ confidence interval $(\mathrm{CI})$ for the positive predictive value was computed.

\section{Statistical analysis}

We computed frequencies of first-time status asthmaticus hospitalizations, overall and within categories of gender, age group, and comorbidity level. We divided status asthmaticus patients into five age groups: $0-1$ years, 2-14 years, $15-39$ years, $40-59$ years, and $\geq 60$ years. We analyzed data for children aged 0-1 year separately because of the uncertainty of diagnosing respiratory conditions in young children. ${ }^{36}$ We also reported interquartile range (IQR) and median age. We presented results both for the study period as a whole and for four-year calendar periods (1996-1999, 2000-2003, 2004-2007, and 2008-2011). We chose four-year intervals to allow sufficient statistical precision, while keeping enough intervals to allow comparison over time during the 16-year study period. For the period January 1, 2005 to December 31, 2011, we also examined the proportion of first-time status asthmaticus patients who were admitted to an ICU.

We estimated annual rates of first-time status asthmaticus hospitalizations with $95 \%$ CIs for all patients and by gender and age group, and illustrated annual hospitalization rates. The rates were calculated by dividing the number of firsttime status asthmaticus hospitalizations by total time at risk of disease among all Danish residents, assuming that each person alive on January 1 of the year of interest contributed one person-year (PY; the denominator). ${ }^{27}$ For gender and age groups, we used the corresponding subgroup of the population as the denominator. The resulting hospitalization rates are reported per 1,000,000 PY for all years together and for four-year calendar periods during the study period, respectively.

Patients were followed from admission until death, emigration, or for up to 30 days, whichever came first. We computed 30-day mortality overall and for each four-year calendar period. We used direct standardization to compute 30 -day mortality risk, ${ }^{37}$ including $95 \%$ CIs, standardized to the gender and age group distribution in the study population of the 2008-2011 period.

We conducted two sensitivity analyses. First, to assess potential misclassification of an acute exacerbation of COPD as status asthmaticus, we identified and excluded all status asthmaticus patients with a previous or concurrent COPD diagnosis recorded in the NPR, repeated all analyses, and assessed potential changes in the results. Second, to improve the specificity of the status asthmaticus diagnosis, we examined the number of hospitalizations among patients with status asthmaticus as their primary diagnosis, excluding patients with status asthmaticus only as their secondary diagnosis.

All statistical analyses were performed using Stata Release 11 (StataCorp, LP, College Station, TX, USA).

\section{Results}

\section{Characteristics of study subjects}

We identified 5,001 patients hospitalized with a first-time status asthmaticus diagnosis in Denmark from 1996 through 2011 (Table 1). Of these, 50.5\% were male, $40.3 \%$ were younger than 15 years, and $87.6 \%, 10.1 \%$, and $2.3 \%$ had a low, medium, and high comorbidity level, respectively (Table 1).

\section{Hospitalizations}

The annual hospitalization rates for all patients are illustrated in Figure 1 and Figure 2. The hospitalization rate of all status asthmaticus patients increased during the study period: the hospitalization rate was 48.0 per 1,000,000 PY (95\% CI: 45.1-51.1 per 1,000,000 PY) in 1996-1999, 52.0 per 1,000,000 PY (95\% CI: 49.0-55.1 per 1,000,000 PY) in 2000-2003, 67.1 per 1,000,000 PY (95\% CI: 57.8-64.4 per 1,000,000 PY) in 2004-2007, and 70.1 per 1,000,000 PY (95\% CI: 66.7-73.7 per 1,000,000 PY) in 2008-2011.

The gender distribution of patients with first-time status asthmaticus was similar throughout the study period, except for a higher hospitalization rate in 2004-2007 for males (67.6 
Table I Characteristics of patients with a first-time status asthmaticus hospitalization, Denmark, I996-20I I

\begin{tabular}{|c|c|c|c|c|c|}
\hline \multirow[t]{2}{*}{ Variable } & \multirow{2}{*}{$\frac{\text { All years }}{1996-2011}$} & \multicolumn{4}{|c|}{ Stratified by calendar period } \\
\hline & & $1996-1999$ & $2000-2003$ & 2004-2007 & 2008-20II \\
\hline All patients & $5,00 I(100.0)$ & $1,015(100.0)$ & $1,113(100.0)$ & $1,324(100.0)$ & $1,549(100.0)$ \\
\hline \multicolumn{6}{|l|}{ Gender } \\
\hline Females & $2,474(49.5)$ & $540(53.2)$ & $557(50.0)$ & $599(45.2)$ & $778(50.2)$ \\
\hline Males & $2,527(50.5)$ & $475(46.8)$ & $556(50.0)$ & $725(54.8)$ & $77 \mathrm{I}(49.8)$ \\
\hline \multicolumn{6}{|l|}{ Age group (years) } \\
\hline $0-1$ & $534(10.7)$ & $50(4.9)$ & $63(5.7)$ & $235(17.8)$ & $186(12.0)$ \\
\hline $2-14$ & $\mathrm{I}, 48 \mathrm{I}(29.6)$ & $145(14.3)$ & $301(27.0)$ & $485(36.6)$ & $550(35.5)$ \\
\hline $15-39$ & $1,018(20.4)$ & $203(20.0)$ & $248(22.3)$ & $237(17.9)$ & $330(21.3)$ \\
\hline $40-59$ & $866(17.3)$ & $218(21.5)$ & $225(20.2)$ & $189(14.3)$ & $234(15.1)$ \\
\hline$\geq 60$ & $\mathrm{I}, 102(22.0)$ & $399(39.3)$ & $276(24.8)$ & $178(\mid 3.4)$ & $249(16.1)$ \\
\hline Median (IQR) & $27.7(6.7-56.6)$ & $51.4(23.1-68.7)$ & $35.2(9.5-60.0)$ & II.8 (3.3-43.7) & $17.2(5.6-48.0)$ \\
\hline \multicolumn{6}{|l|}{ Comorbidity } \\
\hline \multicolumn{6}{|l|}{ Comorbidity level } \\
\hline Low $/ \mathrm{CCl}$ score $=0$ & $4,383(87.6)$ & $831(81.9)$ & $965(86.7)$ & $1,204(90.9)$ & I,383 (89.3) \\
\hline Medium $/ \mathrm{CCl}$ score $=\mathrm{I}-2$ & $503(10.1)$ & $162(16.0)$ & $120(10.8)$ & $94(7.1)$ & $127(8.2)$ \\
\hline High/CCl score $\geq 3$ & $115(2.3)$ & $22(2.2)$ & $28(2.5)$ & $26(2.0)$ & $39(2.5)$ \\
\hline COPD & $939(18.8)$ & $324(31.9)$ & $246(22.1)$ & $191(14.4)$ & $178(\mid 1.5)$ \\
\hline
\end{tabular}

Note: Values are expressed as number (percentage) unless otherwise indicated.

Abbreviations: $\mathrm{CCl}$, Charlson comorbidity index; COPD, chronic obstructive pulmonary disease; IQR, interquartile range.

per 1,000,000 PY [95\% CI: 62.7-72.7 per 1,000,000 PY]) than for females (54.7 per 1,000,000 PY [95\% CI: 50.4-59.2 per 1,000,000 PY]) (Table 1 and Figure 1).

The median age of the cohort declined during the study period, from 51.4 years (IQR: 23.1-68.7 years) in 19961999 to 17.2 years (IQR: $5.6-48.0$ years) in 2008-2011
(Table 1). Hospitalization rates by age group are illustrated in Figure 2. A steady increase in the hospitalization rate of 2-14 year olds was observed: from 44.9 per 1,000,000 PY (95\% CI: $37.9-52.9$ per 1,000,000 PY) in 1996-1999 to 157.3 per $1,000,000$ PY (95\% CI: $144.4-171.0$ per $1,000,000 \mathrm{PY}$ ) in 2008-2011. A conspicuous peak among

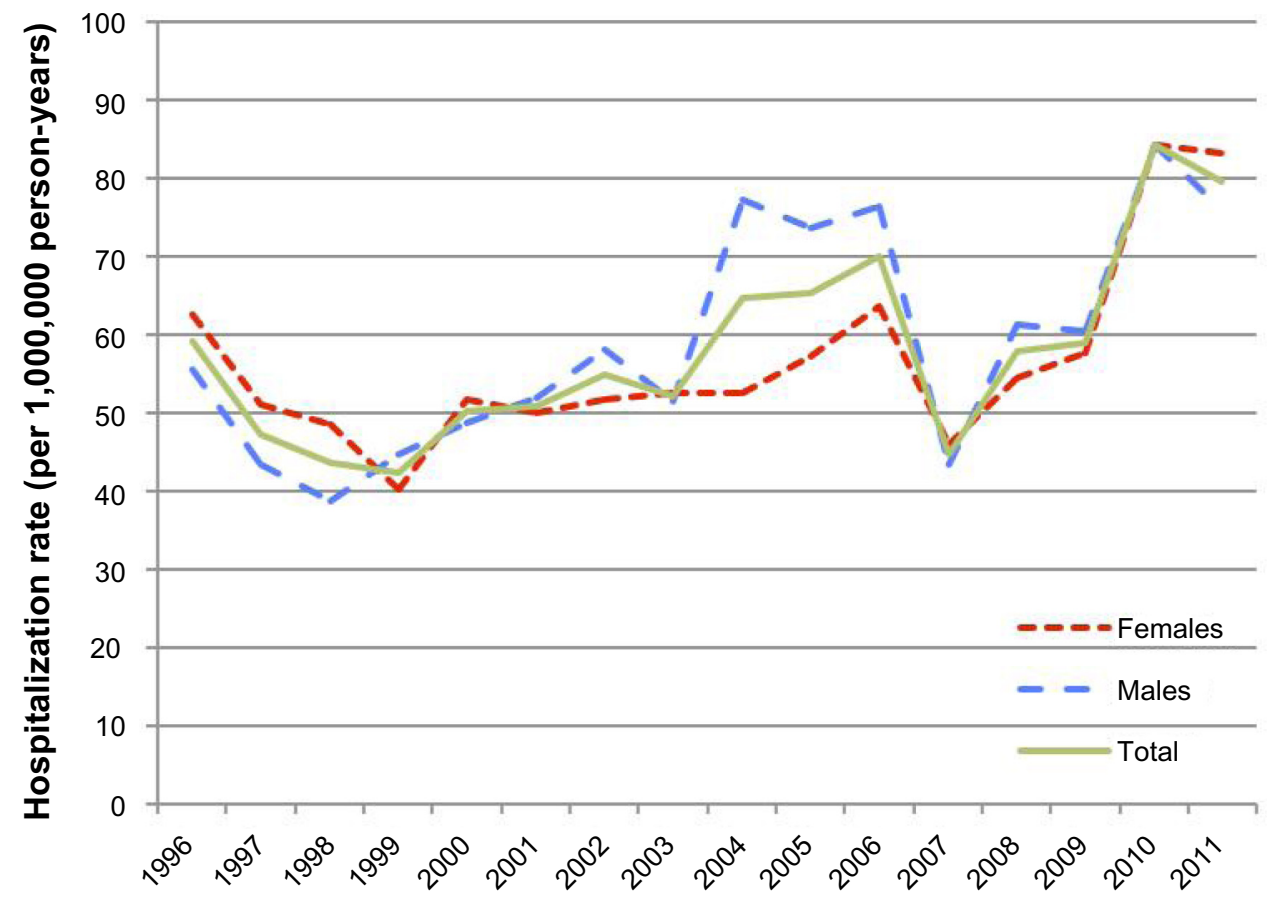

Year of hospitalization

Figure I First-time hospitalization rates of patients with status asthmaticus, Denmark, 1996-20II, stratified by gender. 


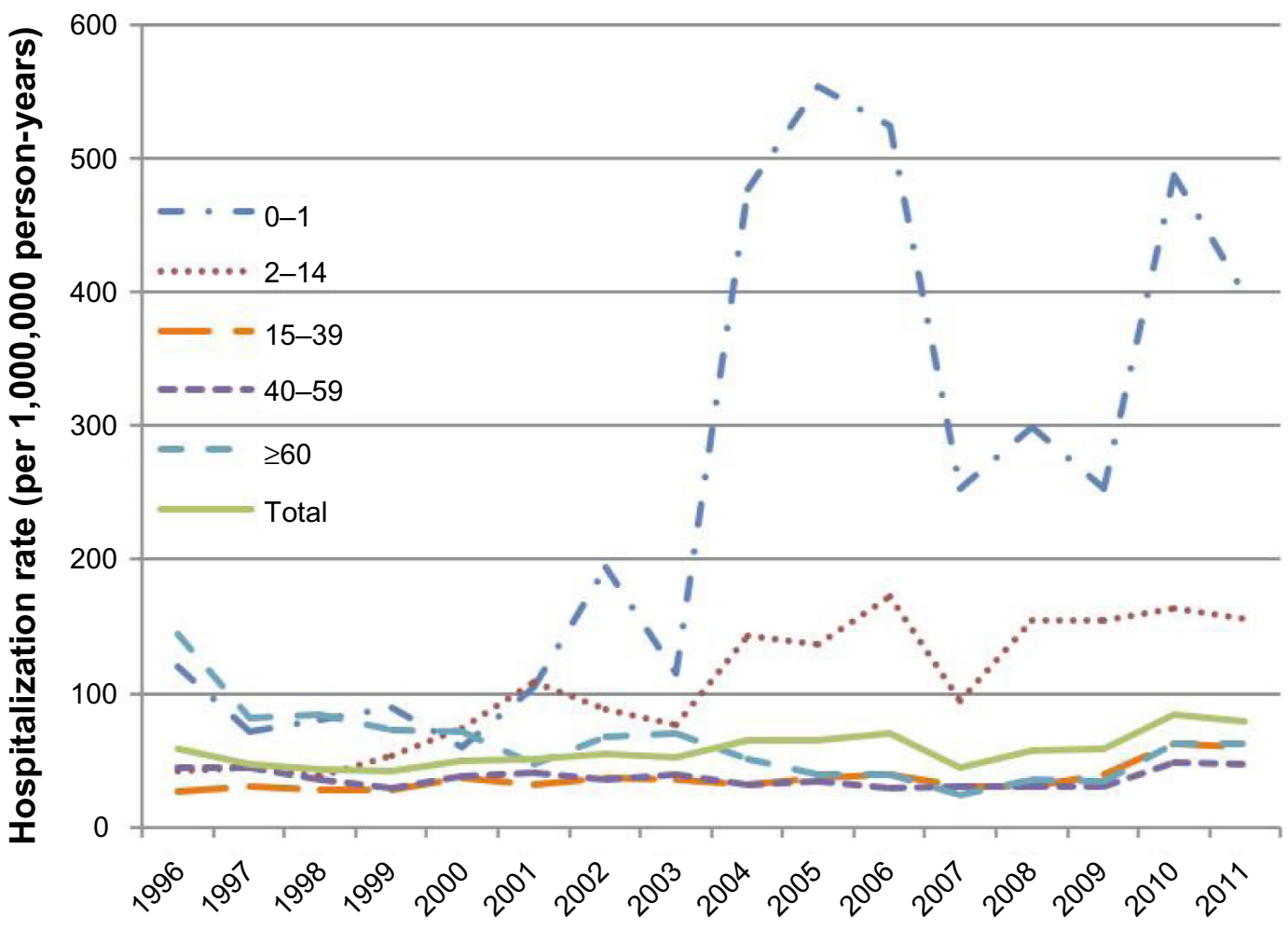

Year of hospitalization

Figure 2 First-time hospitalization rates of patients with status asthmaticus, Denmark, 1996-20II, stratified by age group (years).

children under age 2 was seen in 2004-2007 (452.8 per 1,000,000 PY [95\% CI: 396.8-514.6 per 1,000,000 PY]), compared with 1996-1999 (91.1 per 1,000,000 PY [95\% CI: $67.6-120.1$ per 1,000,000 PY]). The majority (68.5\%) of this subgroup was between 1 and 2 years old. The hospitalization rate for patients aged $\geq 60$ years decreased from 96.0 per 1,000,000 PY (95\% CI: $86.8-105.9$ per $1,000,000 \mathrm{PY})$ in $1996-1999$ to 38.7 per $1,000,000 \mathrm{PY}$ (95\% CI: 33.2-44.9 per 1,000,000 PY) in 2004-2007. The hospitalization rate was even lower for patients aged 15-59 years (Figure 2).

In all four-year calendar periods, the majority of status asthmaticus patients had no comorbid conditions according to CCI (Table 1). The proportion of patients with comorbidity (score $\geq 1$ ) declined during the study period from $18.2 \%$ in $1996-1999$ to $10.7 \%$ in $2008-2011$.

During 2005-2011, 256 status asthmaticus patients were admitted to an ICU, corresponding to $10.1 \%$ of all 2,524 first-time status asthmaticus hospitalizations during the 2005-2011 period.

\section{Mortality}

In total, $162(3.2 \%)$ of the 5,001 patients died within 30 days after their first-time hospitalization for status asthmaticus (Table 2). The standardized 30-day mortality risk declined during the 16-year period from 3.3\% (95\% CI: $2.5 \%-4.1 \%$ ) in $1996-1999$ to $1.5 \%$ (95\% CI: $0.9 \%-2.1 \%)$ in 2008-2011.

Table 2 Thirty-day mortality of patients with a first-time status asthmaticus hospitalization, Denmark, 1996-20II

\begin{tabular}{|c|c|c|c|c|c|}
\hline \multirow[t]{2}{*}{ Variable } & \multirow{2}{*}{$\frac{\text { All years }}{|996-20| \mid}$} & \multicolumn{4}{|c|}{ Stratified by calendar period } \\
\hline & & $1996-1999$ & 2000-2003 & 2004-2007 & 2008-20II \\
\hline All patients & $5,001(100.0)$ & $\mathrm{I}, 015(100.0)$ & I,II3 (100.0) & $\mathrm{I}, 324(100.0)$ & $1,549(100.0)$ \\
\hline \multicolumn{6}{|l|}{ 30-day mortality risk } \\
\hline Deaths & $162(3.2)$ & $72(7.1)$ & $38(3.4)$ & $29(2.2)$ & $23(1.5)$ \\
\hline Standardized mortality, $\%$ (95\% Cl) & & $3.3(2.5-4.1)$ & $2.3(1.6-3.0)$ & $2.5(1.7-3.5)$ & $1.5(0.9-2.1)$ \\
\hline
\end{tabular}

Notes: Values are expressed as number (percentage) unless otherwise indicated. aStandardized to the gender and age group distribution of the 2008-20II period. Abbreviation: $\mathrm{Cl}$, confidence interval. 


\section{Sensitivity analyses}

After excluding 939 (18.8\%) COPD patients, we observed a lower rate of first-time status asthmaticus hospitalizations and a lower 30-day mortality, but similar temporal trends (Appendices 2-5).

The second sensitivity analysis, excluding 860 (17.1\%) patients registered with a secondary diagnosis of status asthmaticus only, showed virtually no changes in hospitalization trends or age distribution (Appendix 6).

\section{Validation of the status asthmaticus registry diagnosis}

The status asthmaticus diagnosis was confirmed in 42 out of a sample of 48 hospitalizations with a diagnosis of status asthmaticus, corresponding to a positive predictive value of 87.5\% (95\% CI: 74.7\%-95.3\%). A second reviewer reviewed 20 discharge summaries; of these, twelve were re-reviewed by a third reviewer because of disagreement between the first two reviewers.

\section{Discussion}

To the best of our knowledge, this is the first populationbased study of first-time hospitalization for status asthmaticus among patients of all ages. We found that the status asthmaticus hospitalization rate increased over a 16-year period, which may be explained by the increase in hospitalization rates among children. During the same period, the associated 30-day mortality decreased. Ten percent of hospitalized status asthmaticus patients were admitted to an ICU.

\section{Limitations and strengths}

Our study relies on the quality of status asthmaticus diagnoses registered in the NPR. Although the NPR includes data on $99.4 \%$ of hospitalizations, ${ }^{30}$ incomplete registrations of status asthmaticus in this registry would have led to underestimation of the hospitalization rates. Follow-up for death was virtually complete.

Changes in registration practices may have influenced our findings. However, this was minimized through use of the same ICD revision for diagnostic coding throughout the study period.

The process of clinical diagnosis of acute exacerbations in asthma can be difficult and can result in misclassification. Although a definition of status asthmaticus is available,${ }^{1-4}$ there are several different terms, including acute asthma, severe asthma, and hospital admission due to asthma. 2,5,17,19-22,24,25,38 Furthermore, status asthmaticus is the only sub-code among the asthma diagnoses in the ICD-10 that denotes an acute asthmatic condition. Clinicians could therefore be prone to diagnose and report less serious asthmatic attacks as status asthmaticus. However, we found a reasonable high positive predictive value for the status asthmaticus diagnosis in the NPR, and observed no major changes in our results when we excluded patients recorded as having COPD or had received status asthmaticus as a secondary diagnosis.

\section{Comparison with other studies}

In contrast to our findings, Hartman et al observed a halving in the rate of hospital admissions for status asthmaticus from 1.98 per 1,000 children in 1992 to 0.93 per 1,000 children in 2006 in their study of 28,309 hospitalized children in the US state of New Jersey. ${ }^{16}$ The higher estimates compared with our findings may be explained by their inclusion of readmissions. ${ }^{16}$

Rodrigo et al included 3,038 patients hospitalized for acute severe asthma at 19 tertiary-care hospitals in Spain and Latin America in 1994, 1999, and 2004, and found that $6.8 \%$ were admitted to an ICU. ${ }^{17}$ The smaller proportion of patients admitted to the ICU compared with our findings may be explained by their restriction to patients aged $15-69$ years. ${ }^{17}$

The 30-day mortality observed in the present study was in the lower range compared with other studies showing status asthmaticus mortality ranging from $0.4 \%$ to $12 \%$ (and even higher among patients receiving mechanical ventilation). ${ }^{1,5,7,14,15,18-20,22,23,25}$ However, comparisons among studies are complicated by the restriction to ICU patients or different age groups in some studies. $7,8,14,15,18-23,25,26$

Our observation of decreased 30-day mortality over time is consistent with several studies finding a decreasing mortality due to asthma during the past decades. ${ }^{1,5,6,19,21,22}$ Stow et al ${ }^{19}$ reported a significant decline in mortality risk from acute severe asthma among ICU patients between 1997 (4.7\%) and $2003(1.1 \%)$ in Australia, Gershon et $\mathrm{al}^{6}$ reported a decrease in all-cause mortality in individuals with asthma between 1996 and 2005 in the state of Ontario, and Roberts et al ${ }^{1}$ reported a 30-day case-fatality following asthma or status asthmaticus admission $(0.9 \%)$ in Scotland, which has been decreasing since the mid-1990s.

Our 30-day mortality finding could possibly be explained by the restriction to first-time status asthmaticus hospitalizations, since the risk of further admissions and poor prognosis is increased by readmission, ${ }^{7}$ and by the encompassing of all patients hospitalized with status asthmaticus, and not only patients admitted to an ICU or both patients hospitalized with asthma and status asthmaticus. $1,7,8,14,15,18,19,21,23,26$ 


\section{Potential mechanisms}

Several mechanisms may explain our findings. The increased hospitalization rate of status asthmaticus may be due to the increased prevalence of asthma during recent decades in line with international reports. ${ }^{6,7,10,12,13}$ In addition, fluctuations in hospitalization rates for status asthmaticus could be related to fluctuations in other airway diseases, eg, asthmatic bronchitis, pneumonia, pseudo croup, and viral infections, provoking respiratory symptoms resembling asthma or exacerbation of asthma. ${ }^{39}$ This applies especially to children and challenges the following control of asthma to avoid readmission and the risk of worsened prognosis. ${ }^{?}$

The increased hospitalization rate of younger patients could explain the decreasing mortality over time, because younger patients have fewer comorbid conditions and in general a greater chance of surviving an emergency than older patients. The centralization of pediatric ICUs in Denmark and improved disease management, guidelines, and medical protocols during recent years could also explain the decreasing mortality over time, ${ }^{40}$ because increased expertise and judicious judgments are advantageous when treating serious conditions as status asthmaticus. . $^{38,39,41}$

Finally, changes in registration practices, over time, geographically, and/or related to pediatric/adult units that we are unaware of could have played a role. Our study was conducted in Denmark, a Western country with a tax-funded health care system, and our observations may be generalizable to other populations with similar demographics and health care systems. Future research needs to further examine possible underlying mechanisms and trends in disease severity.

\section{Conclusion}

We found that the first-time hospitalization rate for status asthmaticus in Denmark increased during the recent 16 years, but remained below 100 hospitalizations per 1,000,000 PY. This increase may be explained by increased hospitalization rates of children. Simultaneously, 30-day mortality halved to below $2 \%$.

\section{Acknowledgments}

We are thankful to Elisabeth Kristoffersen at the Department of Clinical Epidemiology, who retrieved the medical discharge records used in the validation study of the status asthmaticus diagnosis in the NPR. The Department of Clinical Epidemiology, Aarhus University Hospital, and Aarhus University financially supported this research.

\section{Disclosure}

The authors report no conflicts of interest in this work.

\section{References}

1. Roberts NJ, Lewsey JD, Gillies M, et al. Time trends in 30 day case-fatality following hospitalisation for asthma in adults in Scotland: a retrospective cohort study from 1981 to 2009. Respir Med. 2013;107(8):1172-1177.

2. Shah R, Saltoun CA. Chapter 14: acute severe asthma (status asthmaticus). Allergy Asthma Proc. 2012;33 Suppl 1:S47-S50.

3. Jagoda A, Shepherd SM, Spevitz A, Joseph MM. Refractory asthma, part 1: epidemiology, pathophysiology, pharmacologic interventions. Ann Emerg Med. 1997;29(2):262-274.

4. Cohen NH, Eigen H, Shaughnessy TE. Status asthmaticus. Crit Care Clin. 1997;13(3):459-476

5. Papiris S, Kotanidou A, Malagari K, Roussos C. Clinical review: severe asthma. Crit Care. 2002;6(1):30-44

6. Gershon AS, Guan J, Wang C, To T. Trends in asthma prevalence and incidence in Ontario, Canada, 1996-2005: a population study. Am J Epidemiol. 2010;172(6):728-736.

7. Triasih R, Duke T, Robertson CF. Outcomes following admission to intensive care for asthma. Arch Dis Child. 2011;96(8):729-734.

8. Elsayegh D, Saito S, Eden E, Shapiro J. Increasing severity of status asthmaticus in an urban medical intensive care unit. J Hosp Med. 2008;3(3):206-211.

9. Mannix R, Bachur R. Status asthmaticus in children. Curr Opin Pediatr. 2007;19(3):281-287.

10. Pearce N, Ait-Khaled N, Beasley R, et al. Worldwide trends in the prevalence of asthma symptoms: phase III of the international study of asthma and allergies in childhood (ISAAC). Thorax. 2007;62(9):758-766.

11. Robertson CF, Roberts MF, Kappers JH. Asthma prevalence in Melbourne schoolchildren: have we reached the peak? Med J Aust. 2004;180(6):273-276.

12. World Health Organization. Asthma. Available from: http://www.who. int/respiratory/asthma/en. Accessed June 25, 2013.

13. Global Alliance against Chronic Respiratory Disease (GARD). Global surveillance, prevention and control of chronic respiratory diseases: a comprehensive approach. Geneva: GARD; 2007.

14. Sheikh S, Khan N, Ryan-Wenger N, McCoy KS. Demographics, clinical course, and outcomes of children with status asthmaticus treated in a pediatric intensive care unit: 8-year review. J Asthma. 2013;50(4): 364-369.

15. Peters JI, Stupka JE, Singh H, et al. Status asthmaticus in the medical intensive care unit: a 30-year experience. Respir Med. 2012;106(3): 344-348.

16. Hartman ME, Linde-Zwirble WT, Angus DC, Watson RS. Trends in admissions for pediatric status asthmaticus in New Jersey over a 15-year period. Pediatrics. 2010;126(4):e904-e911.

17. Rodrigo GJ, Plaza V, Bellido-Casado J, et al. The study of severe asthma in Latin America and Spain (1994-2004): characteristics of patients hospitalized with acute severe asthma. J Bras Pneumol. 2009;35(7):635-644. Portuguese.

18. Chiang BL, Hsieh CT, Wang LC, et al. Clinical course and outcome of children with status asthmaticus treated in a pediatric intensive care unit: a 15-year review. J Microbiol Immunol Infect. 2009;42(6):488-493.

19. Stow PJ, Pilcher D, Wilson J, et al. Improved outcomes from acute severe asthma in Australian intensive care units (1996 2003). Thorax 2007;62(10):842-847.

20. Gupta D, Keogh B, Chung KF, et al. Characteristics and outcome for admissions to adult, general critical care units with acute severe asthma: a secondary analysis of the ICNARC case mix programme database. Crit Care. 2004;8(2):R112-R121

21. Han P, Cole RP. Evolving differences in the presentation of severe asthma requiring intensive care unit admission. Respiration. 2004;71(5): $458-462$. 
22. Rodrigo GJ, Rodrigo C, Hall JB. Acute asthma in adults: a review. Chest. 2004;125(3):1081-1102.

23. Afessa B, Morales I, Cury JD. Clinical course and outcome of patients admitted to an ICU for status asthmaticus. Chest. 2001;120(5): 1616-1621.

24. Malmström K, Korhonen K, Kaila M, et al. Acute childhood asthma in Finland: a retrospective review of hospital admissions from 1976 to 1995. Pediatr Allergy Immunol. 2000;11(4):236-240.

25. Lee KH, Tan WC, Lim TK. Severe asthma. Singapore Med J. 1997; 38(6):238-240.

26. Braman SS, Kaemmerlen JT. Intensive care of status asthmaticus. A 10-year experience. JAMA. 1990;264(3):366-368.

27. Statistics Denmark. Statbank Denmark. Available from: http://statbank. $\mathrm{dk} /$ statbank5a/default.asp?w=1843. Accessed June 25, 2013.

28. Pedersen CB. The Danish Civil Registration System. Scand J Public Health. 2011;39(Suppl 7):22-25.

29. Lynge E, Sandegaard JL, Rebolj M. The Danish National Patient Register. Scand J Public Health. 2011;39(Suppl 7):30-33.

30. Nickelsen TN. Data validity and coverage in the Danish National Health Registry. A literature review. Ugeskr Laeger. 2001;164(1):33-37. Danish.

31. Christiansen CF, Christensen S, Johansen MB, Larsen KM, Tønnesen E, Sørensen HT. The impact of pre-admission morbidity level on 3-year mortality after intensive care: a Danish cohort study. Acta Anaesthesiol Scand. 2011;55(8):962-970.

32. Charlson ME, Pompei P, Ales KL, MacKenzie CR. A new method of classifying prognostic comorbidity in longitudinal studies: development and validation. J Chronic Dis. 1987;40:373-383.
33. Thygesen SK, Christiansen CF, Christensen S, Lash TL, Sorensen HT. The predictive value of ICD-10 diagnostic coding used to assess Charlson Comorbidity Index conditions in the population-based Danish National Registry of Patients. BMC Med Res Methodol. 2011;11:83.

34. Gibson PG, McDonald VM, Marks GB. Asthma in older adults. Lancet. 2010;376(9743):803-813.

35. Fletcher RH, Fletcher SW. Diagnosis. In: Fletcher RH, Fletcher SW, editors. Clinical Epidemiology: The Essentials. 4th ed. Philadelphia: Lippincott Williams and Wilkins; 2005:35-38.

36. Wever-Hess J, Kouwenberg J, Duiverman E, Hermans J, Wever A. Prognostic characteristics of asthma diagnosis in early childhood in clinical practice. Acta Paediatr. 1999;88(8):827-834.

37. Rothman KJ, Greenland S. Introduction to stratified analysis. In: Rothman KJ, Greenland S, Lash TL, editors. Modern Epidemiology. 3rd ed. Philadelphia, PA: Lippincott Williams and Wilkins; 2008: 258-282.

38. Papiris SA, Manali ED, Kolilekas L, Triantafillidou C, Tsangaris I. Acute severe asthma: new approaches to assessment and treatment. Drugs. 2009;69(17):2363-2391.

39. Hansen LG. Asthma treatment in children: by general practioners and on hospitals. Laegemagasinet. 2010;24(5):33-38. Danish.

40. Hansen TG, Jepsen SB. Paediatric intensive care in Denmark. Ugeskr Laeger. 2007;169(8):687-689. Danish.

41. Higashi A, Zhu S, Stafford RS, Alexander GC. National trends in ambulatory asthma treatment, 1997-2009. J Gen Intern Med. 2011; 26(12):1465-1470. 


\section{Appendix materials}

Appendix I Diagnostic codes in the International Classification of Diseases

\begin{tabular}{|c|c|c|c|}
\hline & ICD-8 code & ICD-I 0 code & \\
\hline \multicolumn{4}{|l|}{ Diseases in data search } \\
\hline Status asthmaticus & 493.01 & J46 & \\
\hline COPD & $491-2$ & J44 & \\
\hline CCl disease & & & Score \\
\hline I. Myocardial infarction & 410 & $|2|-\mid 23$ & 1 \\
\hline 2. Congestive heart failure & 427.09-427.II; 427.19; 428.99; 782.49 & 150; III.0; II3.0; II3.2 & 1 \\
\hline 3. Peripheral vascular disease & $440-445$ & 170-174; 177 & I \\
\hline 4. Cerebrovascular disease & $430-438$ & 160-169; G45; G46 & I \\
\hline 5. Dementia & $290.09-290.19 ; 293.09$ & F00-F03; F05.I; G30 & 1 \\
\hline 6. Chronic pulmonary disease & $490-493 ; 515-518$ & J40-J47; J60-J67; J68.4; J70.I; J70.3 & 1 \\
\hline 7. Connective tissue disease & $712 ; 716 ; 734 ; 446 ; 135.99$ & M06; M08; M09; M30-M36; D86 & $\mathrm{I}$ \\
\hline 8. Ulcer disease & $530.91 ; 530.98 ; 531-534$ & $\mathrm{~K} 22 . \mathrm{I} ; \mathrm{K} 25-\mathrm{K} 28$ & 1 \\
\hline \multirow[t]{2}{*}{ 9. Mild liver disease } & $57 I ; 573.01 ; 573.04$ & ВI8; K70.0-K70.3; K70.9 & I \\
\hline & & K7I; K73; K74; K76.0 & \\
\hline 10. DM & & & $\mathrm{I}$ \\
\hline Type I & $249.00 ; 249.06 ; 249.07 ; 249.09$ & EI0.0; E.I0.I; EI0.9 & \\
\hline Type 2 & $250.00 ; 250.06 ; 250.07 ; 250.09$ & EII.0; EII.I; EII.9 & \\
\hline II. Hemiplegia & 344 & G8I; G82 & 2 \\
\hline \multirow[t]{2}{*}{ 12. Moderate/severe renal disease } & 403; 404; 580-583; 584; 590.09; & II 2; II 3; N00-N05; N07; NII; & 2 \\
\hline & $593.19 ; 753.10-753.19 ; 792$ & NI4; NI7-NI9; Q6I & \\
\hline 13. DM with end organ damage & & & 2 \\
\hline Type I & $249.0 I-249.05 ; 249.08$ & EI0.2-EI0.8 & \\
\hline Type 2 & $250.0 \mathrm{I}-250.05 ; 250.08$ & EII.2-EII.8 & \\
\hline 14. Any tumor & $140-194$ & $\mathrm{C} 00-\mathrm{C} 75$ & 2 \\
\hline I5. Leukemia & 204-207 & $\mathrm{C} 91-\mathrm{C} 95$ & 2 \\
\hline 16. Lymphoma & 200-203; 275.59 & C8I-C85; C88; C90-C96 & 2 \\
\hline \multirow[t]{2}{*}{ 17. Moderate/severe liver disease } & 070.00; 070.02; 070.04; 070.06; & BI5.0; BI6.0; BI6.2; BI9.0; & 3 \\
\hline & $070.08 ; 573.00 ; 456.00-456.09$ & K70.4; K72; K76.6; 185 & \\
\hline 18. Metastatic solid tumor & $195-198 ; 199$ & $\mathrm{C} 76-\mathrm{C} 80$ & 6 \\
\hline 19. AIDS & 079.83 & B2I-B24 & 6 \\
\hline
\end{tabular}

Abbreviations: AIDS, acquired immune deficiency syndrome; $\mathrm{CCl}$, Charlson comorbidity index; COPD, chronic obstructive pulmonary disease; DM, diabetes mellitus; ICD-8, International Classification of Diseases, 8th revision; ICD-10, International Classification of Diseases, I0th revision.

Appendix 2 Characteristics of patients with a first-time status asthmaticus hospitalization, Denmark, 1996-20II. Patients with a registry diagnosis of chronic obstructive pulmonary disease excluded

\begin{tabular}{|c|c|c|c|c|c|}
\hline \multirow[t]{2}{*}{ Variable } & \multirow{2}{*}{$\frac{\text { All years }}{1996-2011}$} & \multicolumn{4}{|c|}{ Stratified by calendar period } \\
\hline & & $1996-1999$ & $2000-2003$ & 2004-2007 & $2008-20 I I$ \\
\hline All patients & $4,062(100.0)$ & $691(100.0)$ & $867(100.0)$ & I, I33 (100.0) & I,37I (I00.0) \\
\hline \multicolumn{6}{|l|}{ Gender } \\
\hline Females & I,947 (47.9) & $352(50.9)$ & $418(48.2)$ & $498(44.0)$ & $679(49.5)$ \\
\hline Males & $2,115(52.1)$ & $339(49.1)$ & $449(5 \mathrm{I} .8)$ & $635(56.1)$ & $692(50.5)$ \\
\hline \multicolumn{6}{|l|}{ Age group (years) } \\
\hline $0-1$ & $551(12.8)$ & $46(6.7)$ & $62(7.2)$ & $232(20.5)$ & $181(13.2)$ \\
\hline $2-14$ & $\mathrm{I}, 430(35.2)$ & I43 (20.7) & $282(32.5)$ & $470(4 I .5)$ & $535(39.0)$ \\
\hline $15-39$ & $954(23.5)$ & $197(28.5)$ & $226(26.1)$ & $221(19.5)$ & $310(22.6)$ \\
\hline $40-59$ & $595(\mid 4.7)$ & $130(18.8)$ & $155(17.9)$ & $126(\mathrm{II} . \mathrm{I})$ & $184(13.4)$ \\
\hline$\geq 60$ & $562(13.8)$ & $175(25.3)$ & $142(16.4)$ & $84(7.4)$ & $161(11.7)$ \\
\hline Median (IQR) & $17.0(5.3-44.3)$ & $34.8($ (II.7-60.2) & $26.4(7.9-48.8)$ & $9.5(2.6-32.5)$ & $13.8(4.9-40.3)$ \\
\hline \multicolumn{6}{|l|}{ Comorbidity level } \\
\hline Low $/ C C l$ score $=0$ & $3,742(92.1)$ & $6 \mid 4(88.9)$ & 79I (9I.2) & $\mathrm{I}, 069(94.4)$ & $\mathrm{I}, 268(92.5)$ \\
\hline Medium $/ \mathrm{CCl}$ score $=\mathrm{I}-2$ & $27 \mid(6.7)$ & $72(10.4)$ & $60(6.9)$ & $53(6.7)$ & $86(6.3)$ \\
\hline High/CCl score $\geq 3$ & $49(1.2)$ & $5(0.72)$ & $16(1.9)$ & II (I.0) & $17(1.2)$ \\
\hline
\end{tabular}

Note: Values are expressed as number (percentage) unless otherwise indicated.

Abbreviations: $\mathrm{CCl}$, Charlson comorbidity index; IQR, interquartile range. 
Appendix 3 Thirty-day mortality of patients with a first-time status asthmaticus hospitalization, Denmark, 1996-20II. Patients with a registry diagnosis of chronic obstructive pulmonary disease excluded

\begin{tabular}{|c|c|c|c|c|c|}
\hline \multirow[t]{2}{*}{ Variable } & \multirow{2}{*}{$\begin{array}{l}\text { All years } \\
\text { I996-20II }\end{array}$} & \multicolumn{4}{|c|}{ Stratified by calendar period } \\
\hline & & $1996-1999$ & $2000-2003$ & 2004-2007 & 2008-20II \\
\hline All patients & $4,062(100.0)$ & $691(100.0)$ & $867(100.0)$ & $\mathrm{I}, \mathrm{I} 33(100.0)$ & I,37I (I00.0) \\
\hline \multicolumn{6}{|l|}{ 30-day mortality risk } \\
\hline Deaths & $82(2.0)$ & $32(4.6)$ & $22(2.5)$ & $17(1.5)$ & II (0.8) \\
\hline Standardized mortality, \% (95\% Cl) & & $2.4(1.6-3.1)$ & $1.8(1.1-2.5)$ & $2.2(1.2-3.2)$ & $0.8(0.3-1.3)$ \\
\hline
\end{tabular}

Notes: Values are expressed as number (percentage) unless otherwise indicated. ${ }^{2}$ Standardized to the gender and age group distribution of the 2008-201 I period. Abbreviation: $\mathrm{Cl}$, confidence interval.

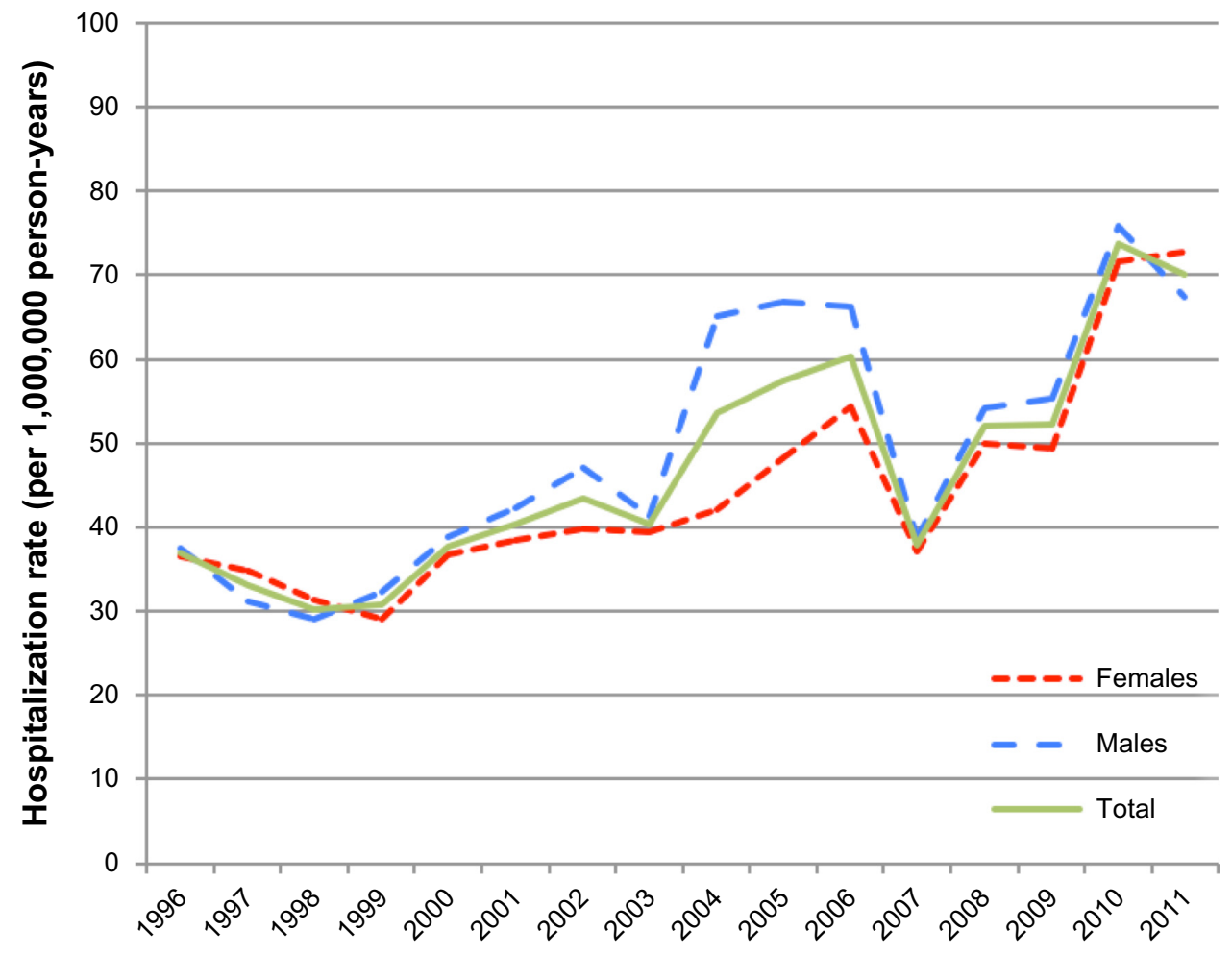

\section{Year of hospitalization}

Appendix 4 First-time hospitalization rates of patients with status asthmaticus, Denmark, 1996-20II, stratified by gender. Patients with a registry diagnosis of chronic obstructive pulmonary disease excluded. 


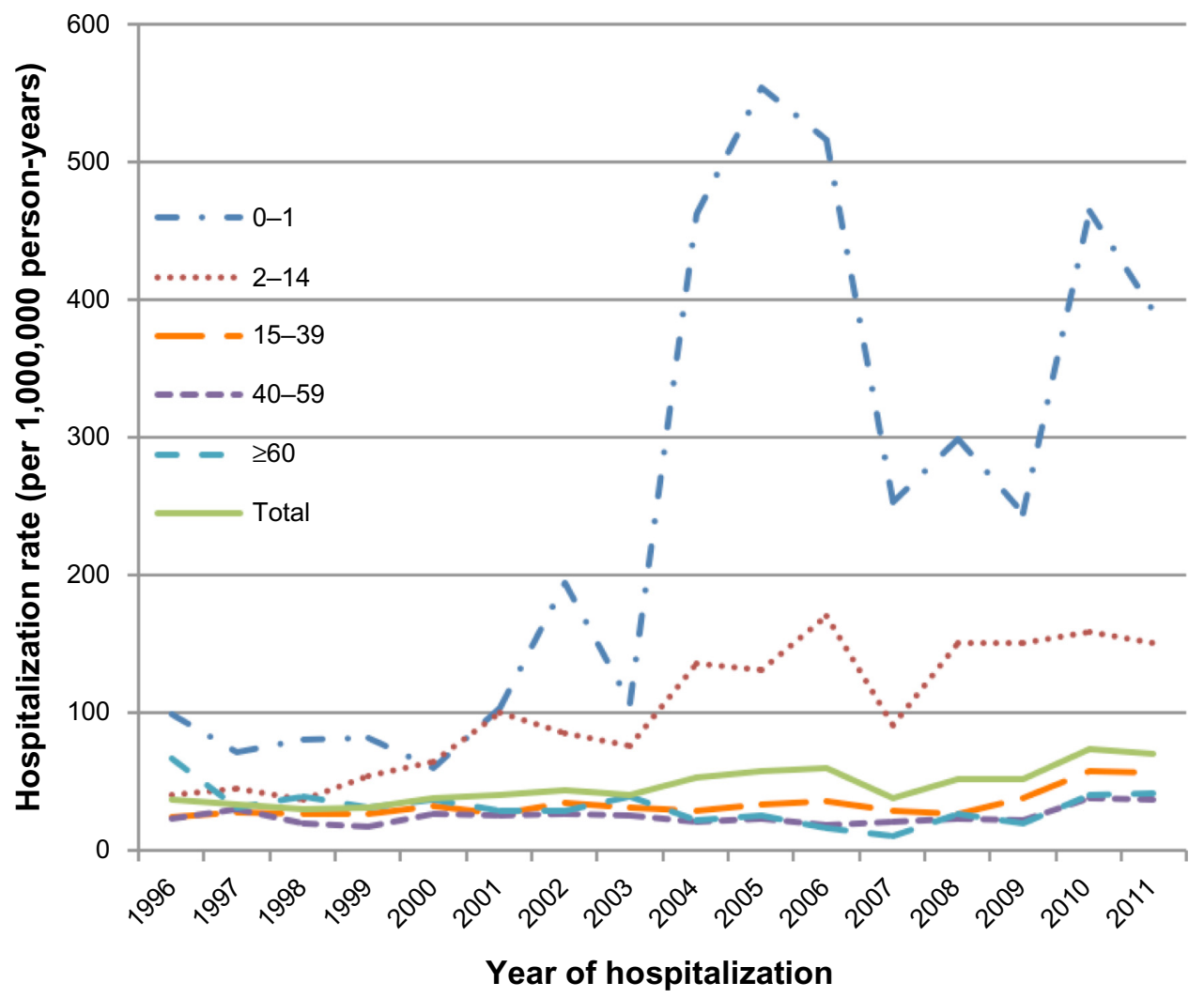

Appendix 5 First-time hospitalization rates of patients with status asthmaticus, Denmark, 1996-20II, stratified by age group (years). Patients with a registry diagnosis of chronic obstructive pulmonary disease excluded.

Appendix 6 Characteristics of patients with a first-time status asthmaticus hospitalization, Denmark, 1996-20II. Patients registered with status asthmaticus as a "secondary" diagnosis excluded

\begin{tabular}{|c|c|c|c|c|c|}
\hline \multirow[t]{2}{*}{ Variable } & \multirow{2}{*}{$\frac{\text { All years }}{\text { I996-20II }}$} & \multicolumn{4}{|c|}{ Stratified by calendar period } \\
\hline & & $1996-1999$ & $2000-2003$ & 2004-2007 & 2008-2011 \\
\hline All patients & $4,|4|(100.0)$ & $824(100.0)$ & $880(100.0)$ & $\mathrm{I}, 105(100.0)$ & $1,332(100.0)$ \\
\hline \multicolumn{6}{|l|}{ Age group (years) } \\
\hline $0-1$ & $479(11.6)$ & $42(5.1)$ & $59(6.7)$ & $212(19.2)$ & $166(12.5)$ \\
\hline $2-14$ & $1,372(33.1)$ & $132(16.0)$ & $269(30.6)$ & $454(4 I .1)$ & $517(38.8)$ \\
\hline $15-39$ & $883(21.3)$ & $180(2 \mid .8)$ & $220(25.0)$ & $20 I(I 8.2)$ & $282(2 \mid .2)$ \\
\hline $40-59$ & $682(16.5)$ & $|8|(22.0)$ & $17 \mid(19.4)$ & $135(12.2)$ & $195(14.6)$ \\
\hline$\geq 60$ & $725(17.5)$ & $289(35.1)$ & I6I (I8.3) & $103(9.3)$ & $172(12.9)$ \\
\hline Median (IQR) & $21.7(5.8-51.0)$ & $47.8(20.0-66.5)$ & $29.4(8.3-53.0)$ & $10.0(2.9-35.8)$ & $14.2(5.1-43.1)$ \\
\hline
\end{tabular}

Note: Values are expressed as number (percentage) unless otherwise indicated.

Abbreviation: IQR, interquartile range.

\section{Publish your work in this journal}

Clinical Epidemiology is an international, peer-reviewed, open access journal focusing on disease and drug epidemiology, identification of risk factors and screening procedures to develop optimal preventative initiatives and programs. Specific topics include: diagnosis, prognosis, treatment, screening, prevention, risk factor modification, systematic

Submit your manuscript here: http://www.dovepress.com/clinical-epidemiology-journa

\section{Dovepress}

reviews, risk \& safety of medical interventions, epidemiology \& biostatical methods, evaluation of guidelines, translational medicine, health policies \& economic evaluations. The manuscript management system is completely online and includes a very quick and fair peer-review system, which is all easy to use. 